\title{
CHARACTERISTICS OF INTERLAYER MATERIALS IN NON-ALLOPHANIC VOLCANIC ASH AND RED YELLOW SOILS FROM JAPAN 1
}

\author{
ANABELLA B. TULIN \\ Professor, PhilRootcrops, Leyte State University \\ Visca, Baybay, Leyte - 6521 A
}

\section{ABSTRACT}

The characteristics and properties of interlayer materials from 10 nonallophanic (Melanudand) and red yellow soils (Alfisols and Ultisols) from three locations in Japan were studied by chemical extractions and $\mathrm{X}$-ray diffraction (XRD) analyses. Allophane was dissolved from clay samples using $0.15 \mathrm{M}$ acid oxalate solution while silicon and aluminum were dissolved using both $0.15 \mathrm{M}$ acid oxalate and $0.3 \mathrm{M}$ sodium citrate solutions. XRD analyses were done for the treated and untreated samples. For the chemically extracted samples, the clay samples were treated with bicarbonate citrate solution for the removal of iron oxides after the dissolution treatments then saturated with $\mathrm{K}$ and $\dot{M} g$ ions for XRD - analyses. Results of the XRD patterns of the untreated and treated samples indicated the interlayer materials as a hydroxy-interlayered form of vermiculite (HIV). Between the two dissolution treatments, the $0.3 \mathrm{M}$ sodium citrate treatment was found to be more effective in removing the interlayer materials than the $0.15 \mathrm{M}$ acid oxalate treatment by allowing interlayer expansion and collapse.

KEY WORDS: Hydoxy - interlayered minerals. Japanese Red-Yellow. Non-allophanic soils. Chemical dissolution treatments. $\mathrm{XRD}$ analyses.

11 Part of the research project entitled, "Characterization of hydroxy-interlayer materials from different soils in Japan" conducted by the author funded by Grant-in-Aid for Scientific Research from the Ministry of Education, Science Sports, and Culture, Japan. 


\section{INTRODUCTION}

Interlayer materials play significant roles in modifying the chemical and physical properties of minerals, in particular vermiculite and smectite. $\mathrm{Al}$ and hydroxy-Al play an important role in modifying the surface and mineralogical properties and cation exchange capacity of clays. Modifications of these characteristics depend upon the degree to which filling of the interlayer space with hydroxy Al occurs and the relative stability of the interlayer components (Barnhisel and Bertsch, 1989). The equilibrium between $\mathrm{Al}$ in solution and hydroxy Al interlayered clays may influence a wide range of chemical reactions in soils, including adsorption of phosphate, formation of Al-phosphate compounds, and the formation of separate stable mineral phases such as gibbsite. They also affect the availability of phosphates in soils especially those added through fertilization.

Hydroxy-interlayered 2:1 clay minerals HIV (vermiculites) and HIS (smectites) can be considered to form a solid solution series, with "pure end - members" consisting of vermiculite or smectite at one extreme and pedogenic or aluminous chlorite at the other (Barnhisel and Bertsh, 1989). There exists various possibilities in between ranging from sparse, weakly interlayered to extensive, well-developed interlayered minerals that are arbitrarily distinguished from aluminous chlorite by their inability to maintain their $1.4 \mathrm{~nm}$ spacing after $550^{\circ} \mathrm{C}$ heat treatment (Matsue and Wada, 1988). Because these characteristics can differ widely, there is a tremendous range in the physicochemical properties of soils dominated with HIV and HIS, and this makes these mineral phases among the most intriguing for soil mineralogical investigations.

In their work with Korean Ultisols and Alfisols, Wada and Kakuto (1983 a.b) concluded that the interlayer materiais present in these soils extracted using sodium citrate has a composition and structure of a $1: 1$ layer mineral, and that the non-exchangeable $K$ is also present in its interlayer space together with exchangeable cations (Wada et al., 1991). Matsue and Wada (1988), on the other hand, reported that in 
Dystrandepts derived from tertiary sediments, materials dissolved by citrate treatment had a Si/Al ratio ranging from 0.72 to 0.24 , suggesting the formation of a Hya sheet partially bonded with-Si-tetrahedra as a possible model of the interlayer structure of PIV. However, it is estimated that some interlayer materials, especially those with low Si/Al ratios, are composed of hydroxy aluminosilicates (HAS) ions and their polymers (Inoue and Satoh, 1992).

This research was conducted to study the characteristics and properties of interlayer materials from non-allophanic and red yellow soils taken from different locations in Japan. Of special interest are those soils affected by eolian dust deposition in their pedogenic development:

\section{METHODOLOGY}

Ten selected soil samples from the $A$ and $B$ horizons of nonallophanic and red yellow soils from different locations in Japan were used (Table 1). Only soils that showed distinct properties of non-allophanic Anidisols, Alfisols and Ultisols were chosen for this study. These soil samples were air dried and fractionated into fine earth using a $2 \mathrm{~mm}$ sieve. The clay fraction $(<2 \mathrm{um})$ was separated from the fine earth by washing with $1 \mathrm{~N} \mathrm{NaCl}$, water, methanol and acetone through a series of dispersion, ultrasonification and sedimentation procedure. The particle size distribution and chemical analyses of some of these samples are presented in Table 2. For particle-size analyses, the soil samples were first treated with $6 \% \mathrm{H}_{2} \mathrm{O}_{2}$ to remove organic matter and then dispersed in deionized water by sonification at $20 \mathrm{kHz}(150 \mathrm{w}, \mathrm{pH} 10)$ for $10 \mathrm{~min}$. The clay (less than $2 \mu \mathrm{m}$ ) and silt ( 2 to $20 \mu \mathrm{m}$ ) fractions were obtained by sedimentation and the fine (20 to $200 \mu \mathrm{m}$ ) and coarse (200 to $2000 \mu \mathrm{m})$ sand fractions were separated by wet sieving. The $\mathrm{pH}$ was measured using a 1:2.5 soil:water/KCl ratio after $1 \mathrm{~h}$ reciprocal shaking (ISRIC, 1987). Organic carbon (C) was measured using the Walkley-Black procedure (Walkley and Black, 1934). Cation exchange capacity (CEC) and exchangeable bases using $1 \mathrm{~N}$ buffered ammonium acetate at $\mathrm{pH} 7.0$ (Chapman, 1965). 


\section{Removal of Free Iron Oxides from Clay}

Free iron oxides were removed from clay following the procedure of Mehra and Jackson (1960) using $0.3 \mathrm{M} \mathrm{Na}$ citrate solution and $0.5 \mathrm{ml}$ of 1 $\mathrm{M} \mathrm{NaHCO}_{3}$ solution added to $100 \mathrm{mg}$ air dried clay samples in a $10 \mathrm{ml}$ glass centrifuge tube.

\section{Preparation of Mg- and K-Saturated Clay Specimens}

The clay samples were saturated with $\mathrm{K}$ and $\mathrm{Mg}$ by treating them with $1 \mathrm{~N} \mathrm{KCl}$ and $\mathrm{MgCl}_{2}$ solution, respectively. Mg-saturated clay samples were solvated with glycerol (Mg-gly) and $20^{\circ} \mathrm{C}(\mathrm{Mg}-20)$ while the $\mathrm{K}$ saturated clay specimens were subjected to $20(\mathrm{~K}-20) 110(\mathrm{~K}-110), 300^{\circ}$ $(K-300)$ and $550^{\circ} \mathrm{C}(\mathrm{K}-500)$ heat treatments. X-ray diffraction (XRD) patterns of these mounted clay specimens were determined using the Rigaku Geigerflex X-ray machine.

Table 1. Brief description and location of the soil samples used in the study.

Sample Code Horizon Depth $(\mathrm{cm})$ Soil Color Location Soll Order

\begin{tabular}{|c|c|c|c|c|c|}
\hline Aki-1 & A & $0-34$ & 5 YR $3 / 2$ & Yamaguchi & Typic Hapludult \\
\hline & $B_{1}$ & $34-70$ & 5 YR $3 / 4$ & 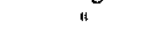 & Typic Hapludult \\
\hline & $\mathrm{B}_{2}$ & $70-110^{+}$ & $10 R 4 / 8$ & • & Typic Hapludult \\
\hline Aki-2 & A & $0-14$ & 5 YR $3 / 4$ & " & Typic Hapludult \\
\hline & $B_{1}$ & $14-40$ & 5 YR 3/4 & " & Typic Hapiudult \\
\hline & $\mathrm{B}_{2}$ & $49-100^{+}$ & $10 R 4 /-6$ & " & Typic Hapludult \\
\hline$M-2$ & B1 & $25-50$ & 7.5 YR $5 / 8$ & Okinawa & Typic Hapludult \\
\hline $2-3$ & IIB21 & $17-38$ & 6.25 YR 5/6 & Iwate & Alic Melanudand \\
\hline$Z-5$ & $8 C$ & $65-100$ & 7.5 YR $5 / 8$ & Okinawa & Typic Hapludult \\
\hline $\mid-3-3$ & $\|A\|$ & $23-35$ & 10 YR $1.7 / 1$ & Iwate & Alic Melanudand \\
\hline
\end{tabular}


Table 2. Physical and chemical properties of some soil samples used in the study.

\begin{tabular}{lccccc}
\hline Sample & \multicolumn{5}{c}{ Particle size distribution analysis (\%) } \\
Code & C. sand & F. sand & Silt & Clay & Textures \\
\hline Aki-1 A & 4.6 & 7.8 & 51.5 & 36.1 & SiC \\
Aki-1 B & 5.5 & 7.6 & 52.1 & 34.8 & SiC \\
Aki-1 B & 2.5 & 6.1 & 32.8 & 58.6 & HC \\
Aki-2 A & 3.4 & 5.5 & 56.6 & 34.5 & SiC \\
Aki-B1 & 2.5 & 6.2 & 48.4 & 42.9 & SiC \\
Aki-2B & 0.4 & 2 & 12.3 & 85.3 & HC \\
I-2-3 & 0.3 & 6.1 & 31.1 & 62.5 & HC \\
I-3-3 & 0.7 & 22.9 & 31.5 & 44.9 & LiC \\
& & & & &
\end{tabular}

Sample Code

Chemical Analysis

\begin{tabular}{|c|c|c|c|c|c|c|c|c|}
\hline \multirow[t]{2}{*}{00} & \multicolumn{2}{|c|}{$\mathrm{pH}$} & \multirow{2}{*}{$\begin{array}{c}\text { Org. C } \\
(\%)\end{array}$} & \multirow{2}{*}{$\begin{array}{c}\text { CEC } \\
(\mathrm{me} / 100 \mathrm{~g})\end{array}$} & \multirow{2}{*}{$\begin{array}{c}\text { Exch. } \\
\mathrm{Ca} .\end{array}$} & \multirow{2}{*}{$\begin{array}{c}\text { Bases } \\
\mathrm{Mg}\end{array}$} & $(\mathrm{me} / 100 \mathrm{~g})$ & \multirow{2}{*}{$\begin{array}{l}\text { BS } \\
(\%)\end{array}$} \\
\hline & $\mathrm{H} 20$ & $\mathrm{KCl}$ & & & & & $\mathrm{K} \quad \mathrm{Na}$ & \\
\hline$A k j-1 A$ & 5.0 & 4.4 & 1.60 & 7.4 & 1 & 0.6 & 0.2 & 26 \\
\hline Aki-1 $B_{1}$ & 5.5 & 4.4 & 0.63 & 9.5 & 0.5 & 0.2 & 0.1 & 9.0 \\
\hline Aki-1 $B_{2}$ & 5.4 & 4.4 & 0.33 & 4.5 & 1.5 & 0.1 & 0.2 & 48 \\
\hline Aki-2 A & 6.7 & 5.7 & 5.23 & 20.7 & 15.9 & 1.4 & 0.1 & 86 \\
\hline Aki-Bi & 5.5 & 4.3 & 0.70 & 10.9 & 2.9 & 0.5 & 0.2 & 34 \\
\hline Aki-2B 2 & 5.9 & 4.4 & 0.54 & 28.4 & 12.6 & 1.8 & 0.5 & 53 \\
\hline $1-2-3$ & 5.2 & 4.0 & 0.81 & 18.4 & 0.5 & 0.9 & 0.8 & 14 \\
\hline $1-3-3$ & 5.2 & 4.2 & 14.11 & 46.8 & 0.04 & 0.1 & 0.4 & 2.0 \\
\hline
\end{tabular}

\section{Dissolution of Allophane, Si and Al by Oxalate Solution}

Allophane, Si and Al were dissolved from clay samples using $0.15 \mathrm{M}$ acid oxalate solution (Higashi and Ikeda, 1974). A hundred mg clay sample was placed in $500 \mathrm{ml}$ polyethylene bottle, to which $200 \mathrm{ml}$ of acid oxalate solution was added. The bottle was covered and shaken for 4 or 
24 hours in a horizontal reciprocating shaker in the dark at $30^{\circ} \mathrm{C}$. The content was then centrifuged for $10 \mathrm{~min}$ at $10,000 \mathrm{rpm}$ and the clear supernatant was decanted in polyethylene bottles. The smaller clay particles in the supernatant were further filtered by ultrafiltration using 0.2 $\mathrm{mm}$ membrane filter.

Silicon was determined colorimetrically following the modified blue silicomolybdous acid procedure by Weaver et al. (1968). Aluminum was determined using the procedure of Davenport (1949), after the destruction of oxalate following the method of Higashi and Ikeda ( 1974).

\section{Dissolution of Si and Al by Citrate Treatment}

Aside from the acid oxalate solution, $\mathrm{Si}$ and $\mathrm{Al}$ were dissolved from clay minerals following the procedure of Tamura (1958). One hundred $\mathrm{mg}$ of clay samples were treated with $100 \mathrm{ml}$ of $0.3 \mathrm{M}$ sodium citrate at $100^{\circ} \mathrm{C}$ for 4 or 24 hours in a tetrafluoroethylene-hexaflucro-propylene (Teflon) flask with a reflux condenser. The amount of Si dissolved was determined by the modified blue silicomolybdous acid procedure of Weaver et al. (1968) as in the acid oxalate treatment. The amount of Al was also analyzed colorimetrically using the method of Davenport (1949).

\section{X-ray Diffraction of Treated Samples}

After the dissolution treatments with hot $0.3 \mathrm{M}$ sodium citrate and 0.15 $\mathrm{M}$ acid oxalate, clay samples remaining in the centrifuge tubes after collecting the supernatant solutions were set aside for XRD analysis. The clay samples were first treated with bicarbonate citrate solution for the removal of iron oxides (Mehra and Jackson, 1960) then saturated with K and $\mathrm{Mg}$ ions by following the procedure for the preparation of $\mathrm{Mg}$ - and $\mathrm{K}$ saturated specimens as previously presented. 


\section{RESULTS AND LISCUSSION}

\section{XRD Patterns of Untreated Samples}

Figure 1 shows the XRD patterns of representative clay samples exhibiting the presence of interlayer materials. A small $1.0 \mathrm{~nm}$ peak in the Mg-saturated patterns of some soil samples indicate that these samples contain some mica. Distinct appearance of $1.4 \mathrm{~nm}$ peak in both the unheated $\mathrm{K}(\mathrm{K}-20)$ - and $\mathrm{Mg}(\mathrm{Mg}-20)$ - saturated samples indicate a hydroxy interlayer form of vermiculite, or smectite or chlorite. As the Ksaturated samples was heated to 110 and then to $300^{\circ} \mathrm{C}$, the $1.4 \mathrm{~nm}$ peak shifted toward $1.0 \mathrm{~nm}$, indicating a hydroxy interlayer form of vermiculite or smectite. The $0.71 \mathrm{~nm}$ peak shows the presence of kaolinite which was further confirmed by the disappearance of the $0.71 \mathrm{~nm}$ peak when the samples were heated to $550^{\circ} \mathrm{C}$ because it would make the kaolinite amorphous to $X$-ray diffraction at $550^{\circ} \mathrm{C}$ and the peaks would disappear at this temperature. The presence of vermiculite in the clay samples was detected by the $1.4 \mathrm{~nm}$ peak of $\mathrm{Mg}$-saturated samples which did not shift to $1.77 \mathrm{~nm}$ upon solvation with glycerol. The presence of chlorites was indicated by the $1.4 \mathrm{~nm}$ peak of K-saturated samples which remained present although at lower intensity, even after heating the samples to $550^{\circ} \mathrm{C}$. The hump or shoulder on the low angle side of the $1.0 \mathrm{~nm}$ reflection may be from the hydroxy interlayered form of vermiculite. In addition to interlayer minerals, the clay samples also contained vermiculite, chlorite and kaolinite as indicated by XRD patterns.

The results of the XRD analyses implied that the dominant interlayer material found in these soils is a hydroxy-interlayered vermiculite or smectite. These findings are similar to the results obtained by Inoue and Naruse (1987) for some eolian dust derived soils taken from different locations in Japan. 


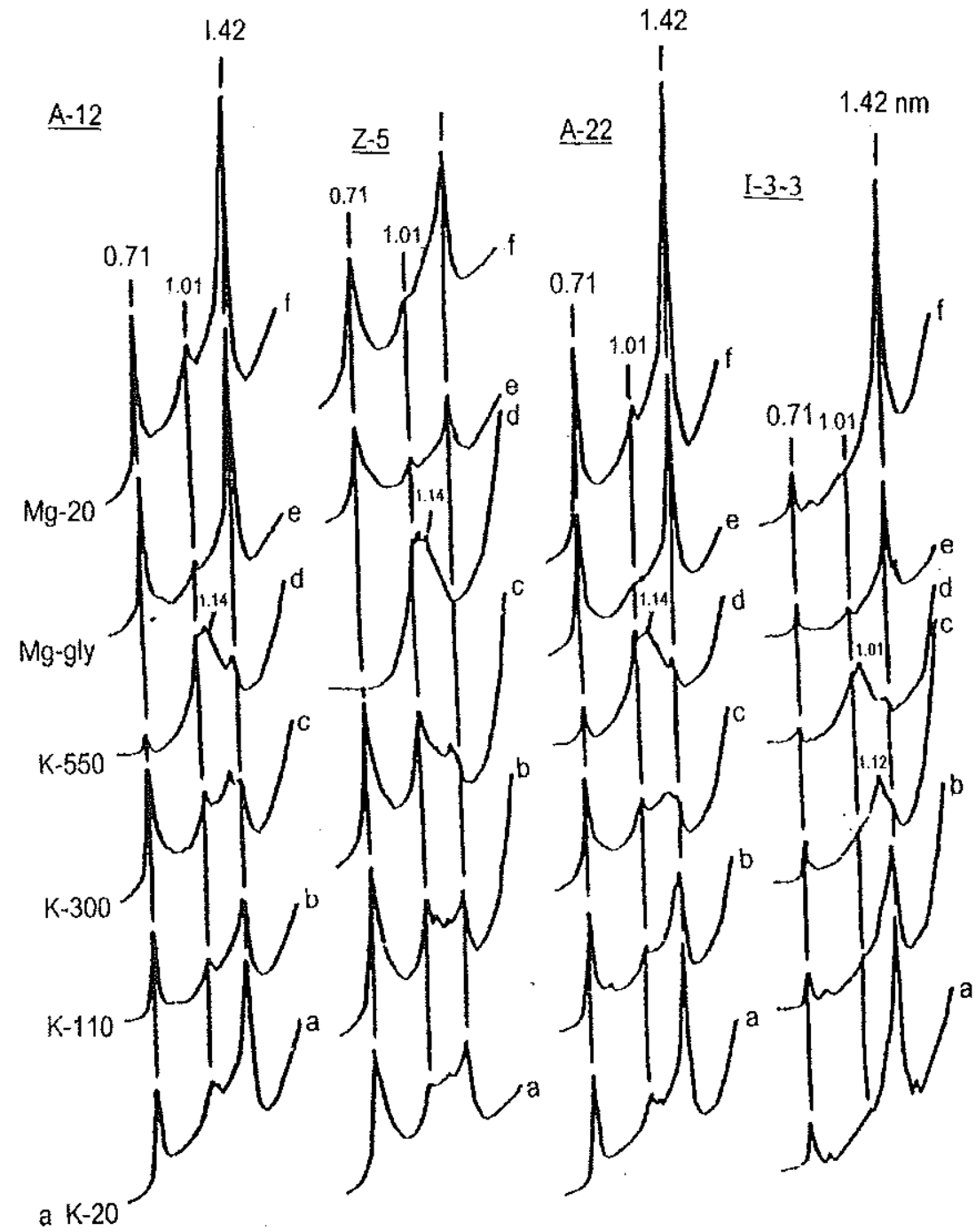

Figure 1. X-ray diffractograms of untreated soil clays representing three soil orders (Hapludults, A- $\{2$ and Z-5; Hapludalf, A-22; Melanudand, I-3-3). 


\section{XRD Patterns of Oxalate Treated Samples}

Figure 2 shows the XRD patterns of oxalate treated clay samples dissolved with $0.15 \mathrm{M}$ acid oxalate solution in the dark for 4 or $24 \mathrm{hrs}$. periods. We could see a similar pattern as in the untreated samples wherein no shift in the Mg-saturated clay was exhibited even after solvating with glycerol. For the $\mathrm{K}$ treated samples, the $1.4 \mathrm{~nm}$ peak did not shift to $1.0 \mathrm{~nm}$ with air drying but was gradually shifted towards $1.0 \mathrm{~nm}$ with increasing heat treatment indicating only minimal and incomplete interlayer collapse. This suggests that oxalate could not effectively allow interlayer expansion and collapse even after the removal of aluminosilicate ions from the interlayer spaces. This was probably due to the inability of the oxalate reagent to dissolve large amounts of Si and $\mathrm{Al}$ ions as compared to the citrate treatment even after the removal of amorphous aluminosilicates (Inoue and Satoh, 1992).

\section{XRD Pattern of Citrate Treated Samples}

Unlike in the previous figures for the untreated and oxalate treated samples, the citrate treated samples show interlayer expansion and collapse after extraction of $\mathrm{Al}$ and $\mathrm{Si}$ (Figure 3). This was clearly shown by the XRD patterns of Mg-saturated I-3-3 sample, in which the $1.77 \mathrm{~nm}$ peak indicating the presence of smectite became apparent after glycerol solvation. Interlayer collapse was evident even in low temperatures of $\mathrm{K}$ saturated samples, wherein at air dried $\mathrm{K}$ samples, the $1.4 \mathrm{~nm}$ completely disappeared and shifted to $1.0 \mathrm{~nm}$ in most of the clay samples. From the XIRD patterns, a sharp shift of the $1.4 \mathrm{~nm}$ peak to $1.0 \mathrm{~nm}$ was detected and the virtual absence of a shoulder in some patterns suggests the destruction of the hydroxy-interlayer materials in the clay. The sharp 
reflection produced at $1.0 \mathrm{~nm}$, indicates that HAS ions adsorbed on the interlayer spaces of $\mathrm{Vt}$ were completely dissolved by the citrate treatment (Inoue and Satoh, 1992). However, the $\mathrm{Mg}$ saturated (air dry, 200 $\mathrm{C}$ ) and glycerol solvated samples did not shift to $1.8 \mathrm{~nm}$, indicating that the mineral is an HIV (hydroxy interlayered vermiculite). A similar result was reported by Matsue and Wada (1988) in Dystrandept derived from tertiary sediment. These results suggest that citrate treatment could dissolve the interlayer materials from smectite and vermiculite thereby allowing interlayer expansion and collapse. The efficiency of the citrate treatment as compared to the oxalate treatment in removing hydroxyinterlayer materials was indicated by the large quantities of $\mathrm{Si}$ and $\mathrm{Al}$ dissolved by citrate (Tables 3 and 4).

Table 3. Dissolution of Si and Al from clay samples by oxalate treatment.

\begin{tabular}{|c|c|c|c|c|c|c|}
\hline \multirow{3}{*}{$\begin{array}{l}\text { Sample } \\
\text { Code }\end{array}$} & \multicolumn{6}{|c|}{ Amounts of $\mathrm{Si}$ and $\mathrm{Al}(\mathrm{g} / \mathrm{kg})$ dissolved } \\
\hline & \multicolumn{2}{|c|}{4 hrs. treatment } & \multirow[b]{2}{*}{ SilAl ratio } & \multirow[b]{2}{*}{$\mathrm{Si}$} & \multicolumn{2}{|c|}{$24 \mathrm{hrs}$, trealment } \\
\hline & $\mathrm{Si}$ & $\mathrm{Al}$ & & & $\mathrm{Al}$ & SilAl ratio \\
\hline$A k i-1 / A$ & 0.6 & 1.6 & 0.38 & 1.5 & 5.1 & 0.29 \\
\hline Aki-1 $B_{1}$ & 0.7 & 1.8 & 0.39 & 1.8 & 5.2 & 0.35 \\
\hline Aki-1 $B_{2}$ & 0.7 & 6.8 & 0.10 & 1.5 & 7.6 & 0.20 \\
\hline Aki-2. & 0.8 & 6.2 & 0.13 & 1.7 & 6.8 & 0.25 \\
\hline Aki-2Bi & 0.6 & 2.5 & 0.24 & 1.6 & 6.2 & 0.28 \\
\hline Aki-2B 2 & 0.7 & 5.1 & 0.14 & 1.4 & 5.2 & 0.27 \\
\hline M2 & 0.6 & 10.5 & 0.06 & 1.3 & 1.5 & 0.87 \\
\hline $1-2-3$ & 1.2 & 5.2 & 0.23 & 2.2 & 1.1 & 5.8 \\
\hline$Z-5$ & 0.11 & 5.8 & 0.02 & 1.1 & 5.8 & 0.19 \\
\hline $1-3-3$ & 0.6 & 18 & 0.03 & 6.6 & 24.1 & 0.27 \\
\hline
\end{tabular}




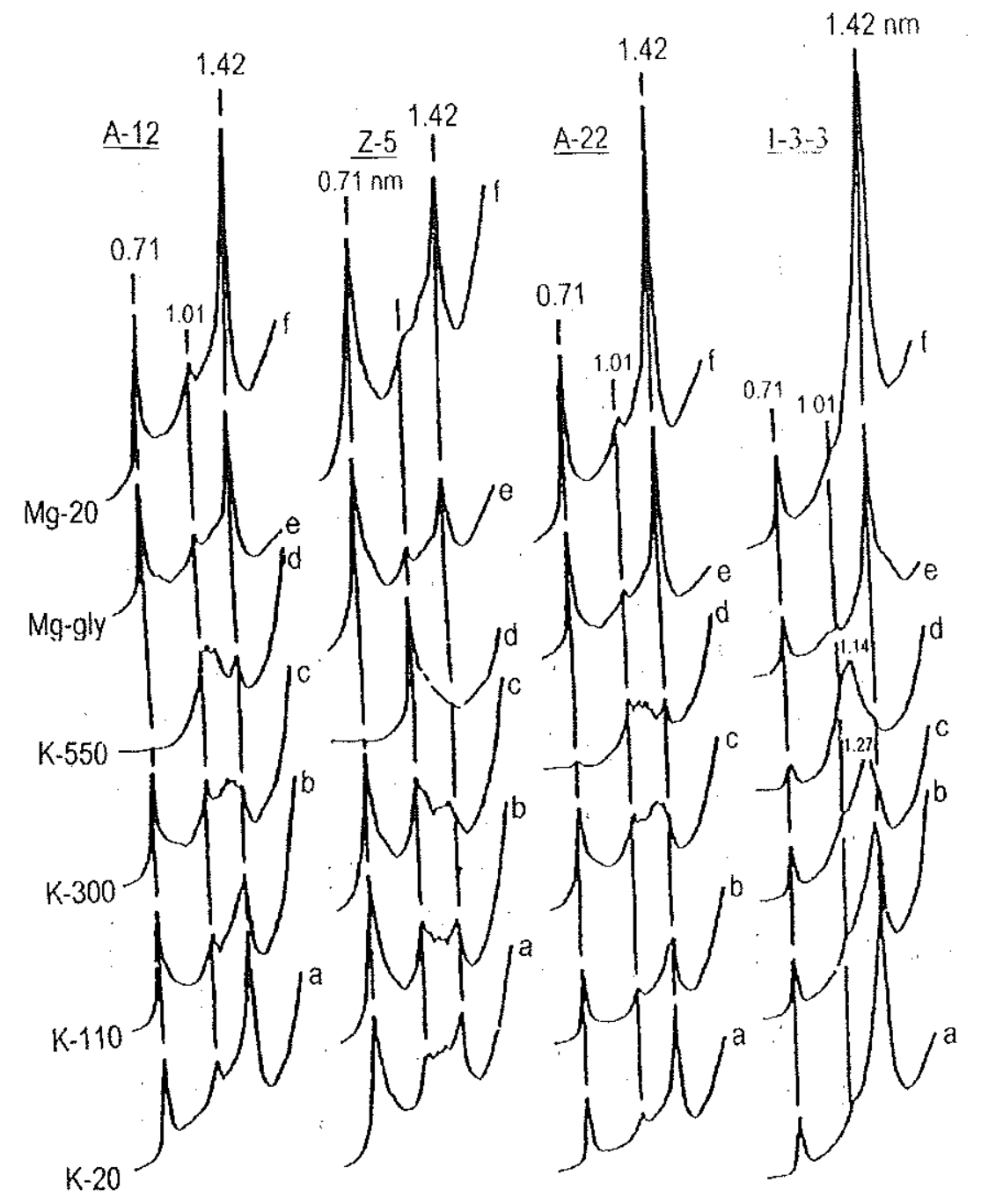

Figure 2. X-ray diffractograms of oxalate treated soil clays representing three soil orders (Hapludults, A-12 and Z-5; Hapludalf, A-22; Melanudand, I-3-3). 


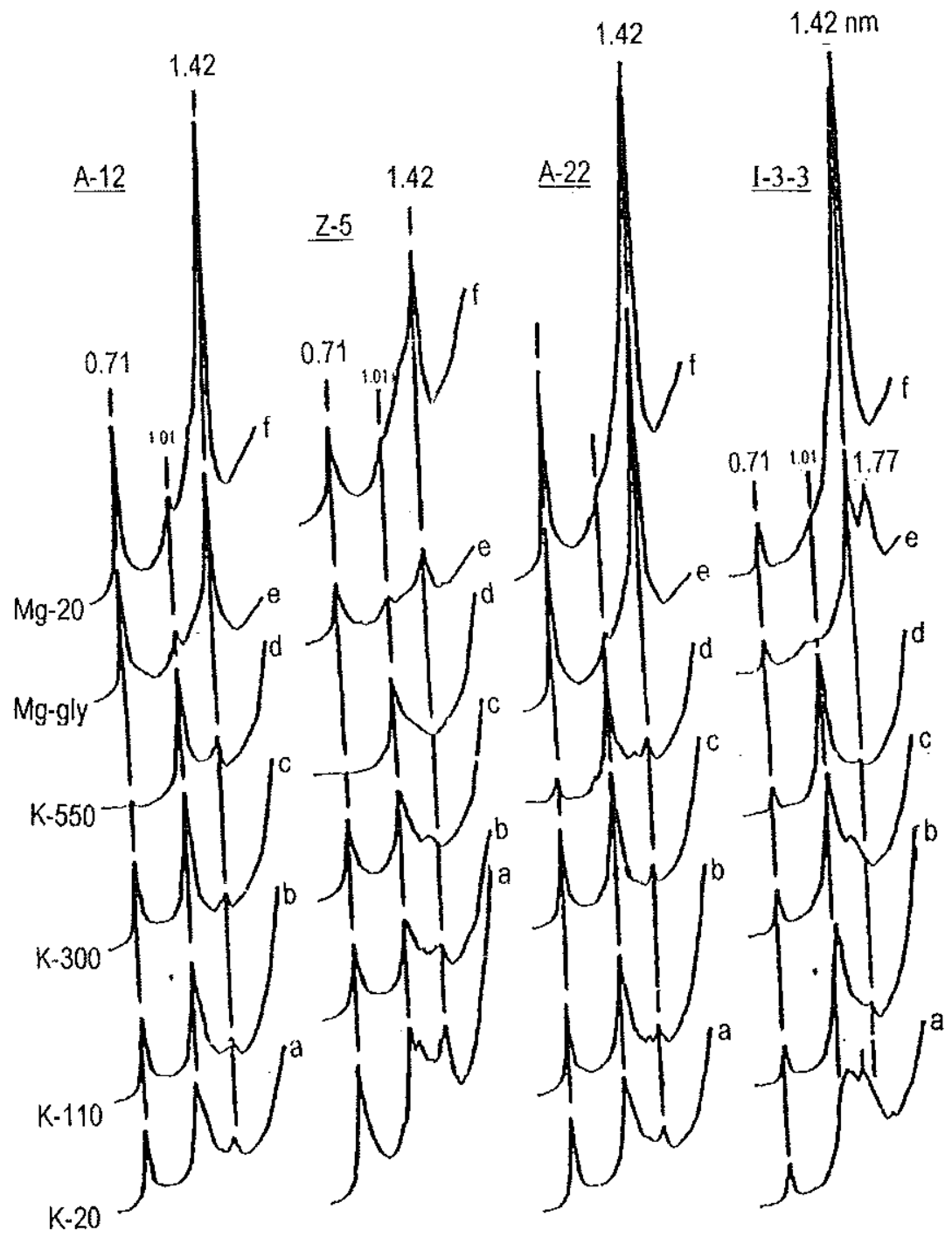

Figure 3. X-ray diffractograms of citrate treated soil clays representing three soil orders (Hapludults, A-12 and Z-5; Hapludalf, A-22; Melanudand, I-3-3). 
Table 4. Dissolution of Si and Al from clay samples by citrate treatment.

\begin{tabular}{|c|c|c|c|c|c|c|}
\hline \multirow{3}{*}{$\begin{array}{l}\text { Sample } \\
\text { Code }\end{array}$} & \multicolumn{6}{|c|}{ Amounts of $\mathrm{Si}$ and $\mathrm{Al}(\mathrm{g} / \mathrm{kg})$ dissolved } \\
\hline & \multicolumn{2}{|c|}{$4 \mathrm{hrs}$, trealment } & \multirow[b]{2}{*}{ SilAl ratio } & \multirow[b]{2}{*}{$\mathrm{Si}$} & \multicolumn{2}{|c|}{$24 \mathrm{hrs}$. treatment } \\
\hline & $\mathrm{Si}$ & $\mathrm{Al}$ & & & $\mathrm{Al}$ & Si/Al ratio \\
\hline Aki-1A & 17.5 & 30.2 & 0.55 & 22.4 & 28.6 & 0.78 \\
\hline Aki-1 $B_{1}$ & 11.8 & 36.20 & 0.32 & 21.3 & 48.9 & 0.44 \\
\hline Aki-1 $B_{2}$ & 18.5 & 25.6 & 0.69 & 23.8 & 52.00 & 0.46 \\
\hline Aki-2 A & 24.3 & $25: 6$ & 0.92 & 22.9 & 38.5 & 0.59 \\
\hline$A k i-2 B_{1}$ & 22.7 & 36.5 & 0.60 & 18.7 & 37.5 & 0.50 \\
\hline Aki-2B 2 & 17.5 & 29.7 & 0.57 & 22.7 & 34.4 & 0.66 \\
\hline$M-2$ & 15.00 & 30.9 & 0.47 & 16.5 & 47.9 & 0.34 \\
\hline $1-2-3$ & 19.7 & 39.6 & 0.46 & 23.2 & 45.7 & 0.51 , \\
\hline Z-5 & 15.5 & 20.10 & 0.75 & 18.8 & 36.10 & 0.52 \\
\hline I-3-3 & 22.7 & 39.6 & 0.55 & 27.2 & 36.10 & 0.75 \\
\hline
\end{tabular}

\section{Dissolved Si and $\mathrm{Al}$ and Si/AI Ratios}

To further determine the nature of interlayer materials in the clay samples, dissolution of $\mathrm{Si}$ and $\mathrm{Al}$ was conducted by acid oxalate and citrate treatments. Table 3 shows the amounts of $\mathrm{Si}$ and $\mathrm{Al}$ dissolved by the acid oxalate treatments at 4 and 24 hours extraction periods. These 2 extraction periods were used to ascertain their effects on the amount of $\mathrm{Si}$ and $\mathrm{Al}$ dissolved. From the results, it was apparent that more $\mathrm{Al}$ and $\mathrm{Si}$ were dissolved at $24 \mathrm{~h}$ than at $4 \mathrm{hr}$ extraction period. The results show that in comparing the 2 dissolution treatments, more $\mathrm{Si}$ and Al were extracted by citrate treatments (Table 4) as compared to oxalate treatments (Table 3). In majority of the samples, more Al were extracted as compared to Si regardless of the dissolution treatment used. This is very evident in Red-Yellow soils (Aki-1 and 2 samples and M-2 and Z-5) which usually contain higher amounts of oxides and hydrous oxides of $\mathrm{Fe}$ 
and $\mathrm{Al}$. On the other hand, higher $\mathrm{Si}$ and $\mathrm{Al}$ were extracted in nonallophanic Andisols (I-2-3 and I-3-3) compared to Red-Yellow soils in the oxalate treatments. This could be due to the weathering of volcanic ash soils during pedogenic development which releases hydroxyaluminosilicate ions. Chloritized vermiculite $(\mathrm{Vt})$ could be pedogenically formed by interaction of expansible 2:1 layer silicates weathered from micas with HyA or HAS ions, which are transformed from volcanic ash during weathering process (inoue and Satoh, 1992).

The Si/Al molar ratios of both the citrate and oxalate treated samples were likewise low with average values of 0.28 and 0.56 for oxalate and citrate samples, respectively. The low Si/Al ratios indicate that the interlayer materials are composed of hydroxy-interlayer materials and their polymers (Inoue and Satoh, 1992 and 1993).

These results also support the suggestion of Inoue and Satoh (1992) which stated that development of chloritized-Vt in the non-allophonic Andisols could be formed by the interaction of $\mathrm{Vt}$, transformed from muscovite and transported as eolian dust from China, with HAS and/or HyA ions formed in soil solutions during weathering and pedogenic alteration of volcanic ash. Bautista and Inoue (1993) also reported that loess or eolian dust deposited on the surface of volcanic ash soils influence the Andic properties of non-allophanic Andisols.

The findings of this study are further supported by the higher amounts of Al dissolved at lower Si/Al ratios in the citrate treated samples (Figure 4). Higher amounts of Al were extracted by citrate at approximately 0.3$0.6 \mathrm{Si} / \mathrm{Al}$ ratio. On the other hand, the amounts of Al extracted increases with Si/Al ratio with most of the Si extracted at 0.4-0.6 Si/Al ratios. Higher amounts of Al were extracted in Andisols as compared to Ultisols and Alfisols. 


\section{Amount of $\mathrm{Si}$ and $\mathrm{Al}$ Dissolved and Extent of Interlayering}

The extent of interlayering was estimated by following the XRD intensity ratio as expressed by:

$$
\frac{\left(1_{14} /\left(1_{14}+1_{10}\right)\right)^{K}}{\left.\left(1_{14} / /_{14}+I_{10}\right)\right)^{M g}}
$$

where $\mathrm{K}$ and $\mathrm{Mg}$ denote $\mathrm{K}+$ and $\mathrm{Mg} 2+$ saturate and air dried samples, respectively (Matsue and Wada, 1988). This ratio was used to determine the extent of interlayering of hydroxy-interlayered vermiculite which is dominant in our samples, since the contribution of chlorite and smectite is minimal as indicated by the XRD patterns. The amount of $\mathrm{Al}$ and $\mathrm{Si}$ dissolved increased with interlayering and higher amounts of Al were dissolved as compared to $\mathrm{Si}$ (Fig.5). This indicates that dissolution of $\mathrm{Al}$ is always accompanied by Si. On the other hand, the Si/Al ratio decreased from approximately 0.75 to 0.30 with increasing interlayering.

These results signify the occurrence of hydroxy-Al and/or-Fe interlayering in 2:1 layer silicate minerals present in Alfisols, Ultisols and nonallophanic Andisols in Japan.

\section{Amount of Al-Dissolved and Interlayer Collapse}

The failure of the interlayer to collapse was measured by comparing the ratio $\left.\right|_{14} /\left(\left.\right|_{14}+\left.\right|_{10}\right)$ for $K$ - saturated $\left.I K\right)$ and air - dried samples, where 114 and 110 stand for the XRD intensities at $d=1.4$ and $1.0 \mathrm{~nm}$, respectively (Wada and Matsue, 1988). High Ik ratios show very low degree of interlayer collapse and lower $\mathrm{kk}$ ratios show high degree of interlayer collapse. In comparing the values obtained in the three soil orders, higher values were obtained in non-allophanic Andisols while lower values were obtained in Ultisols (Fig. 6). 
In establishing the relationship between the amount of Al dissolved and interlayer collapse, the results show that the dissolution of Al both by citrate and oxalate treatments is directly related to interlayer collapse. This suggests that interlayer collapse was accompanied by the removal of hydroxyaluminosilicate and hydroxy-Al materials in the interlayer spaces of $2: 1$ silicate minerals.

\section{Implications to Soil Development and Soil Properties}

The presence of hydroxyinterlayered vermiculites (HIV) in Japanese soils derived from eolian dust will probably affect soil development and the various soil chemical and mineralogical properties. This will lead to the modifications of various reactions that will take place in the soil. Inoue and Higashi (1988) and Inoue (1990) reported that the active Al components in chloritized vermiculite can contribute to the accumulation and stabilization of humus and to the retention of phosphate by acidic and nonallophanic Andisols. Inoue and Satoh $(1992,1993)$ reported that the fixation of hydroxyaluminosilicate (HAS) and hydroxy-Al ions in the interlayer spaces of vermiculite and montmorillonite greatly changed the electrical charge and the surface properties of soils containing them. Aside from this, the cation exchange capacity of the soil was also diminished by hydroxyaluminosilicate ions and their polymers, which will greatly affect the chemistry and fertility of the soils. Sakurai and Huang (1998) reported significant reduction in the CEC of montmorillonite after HAS ion adsorption. They added that from the pedological point of view, the intercalation of HAS ions within permanent-charge minerals can be considered as a weathering process in subtropical and temperate regions. This weathering process would lead to the alterations of the surface chemistry of soil colloids pertaining to transformation and transport of nutrients and pollutants in the environment. 


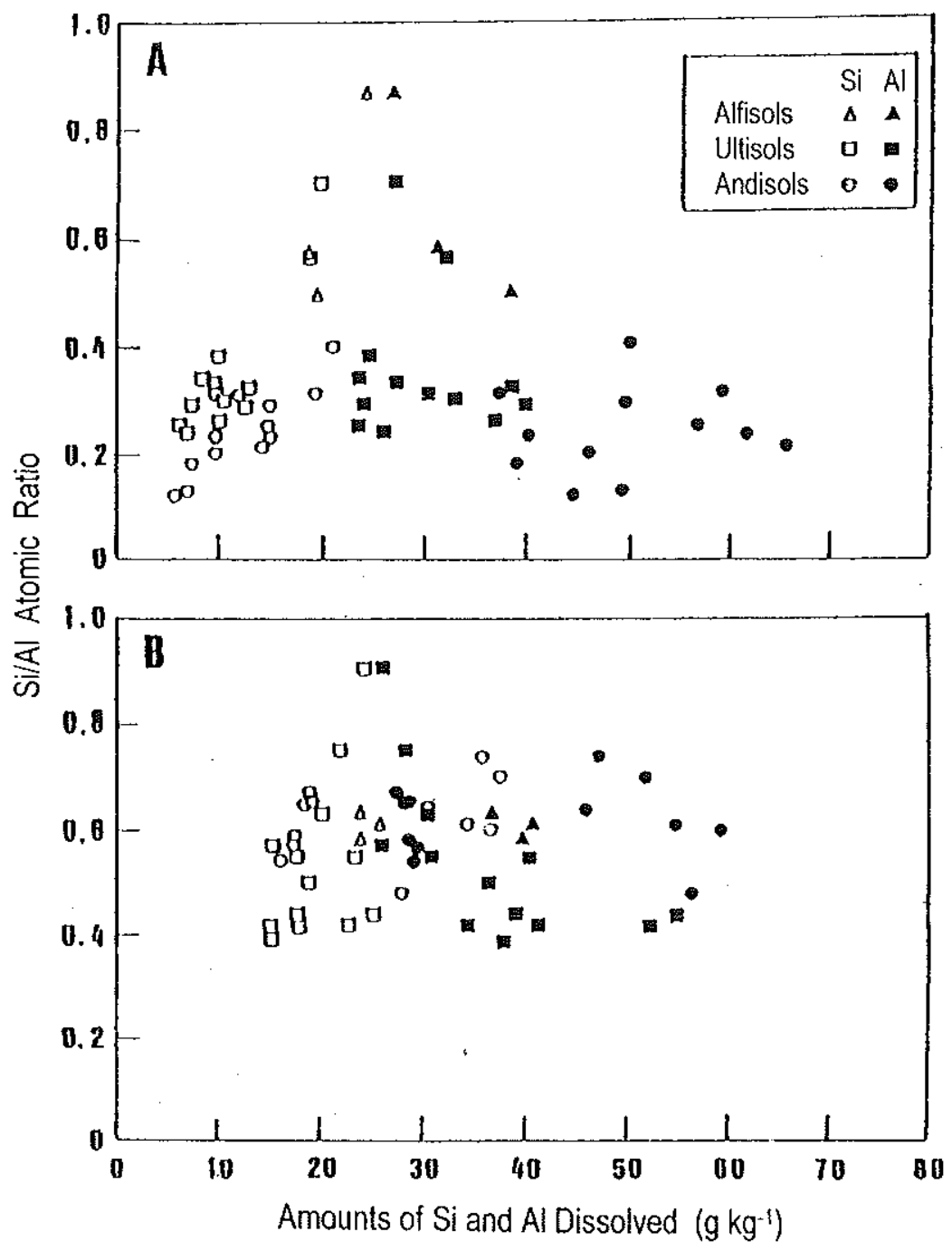

Figure 4. Relationships between the amounts of $\mathrm{Si}$ and $\mathrm{Al}$ dissolved and $4 \mathrm{~h}$ citrate (A) and $24 \mathrm{~h}$ citrate after $4 \mathrm{~h}$ oxalate (B) treatments and the Si/Al atomic ratios of Alfisols, Ultisols and Andisols. 

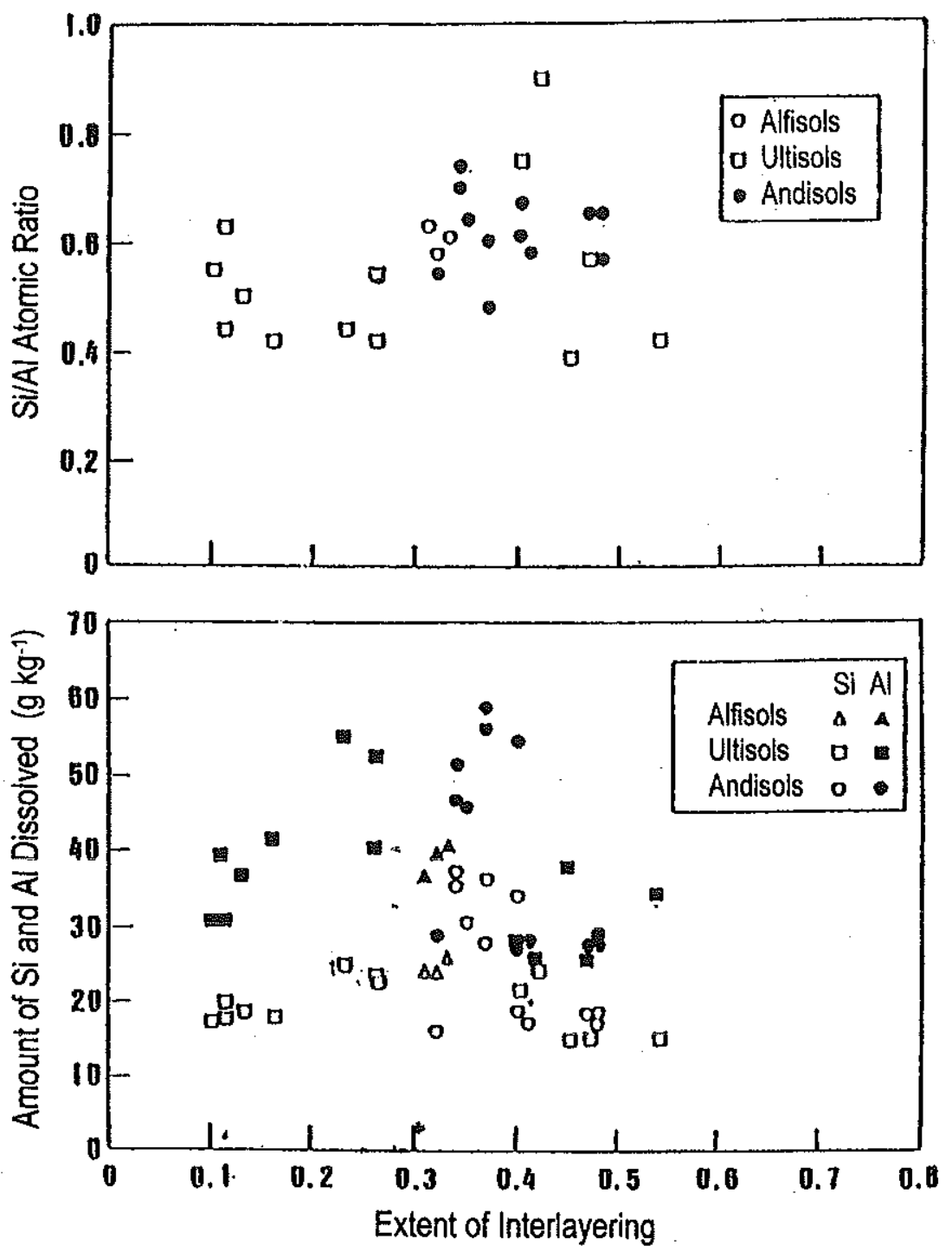

Figure. 5. Relationship between the amounts of Si and Al dissolved by 24 $\mathrm{h}$ citrate treatment after $4 \mathrm{~h}$ oxalate and Si/Al atomic ratios with the extent of interlayering in Alfisols, Ultisols and Andisols. 


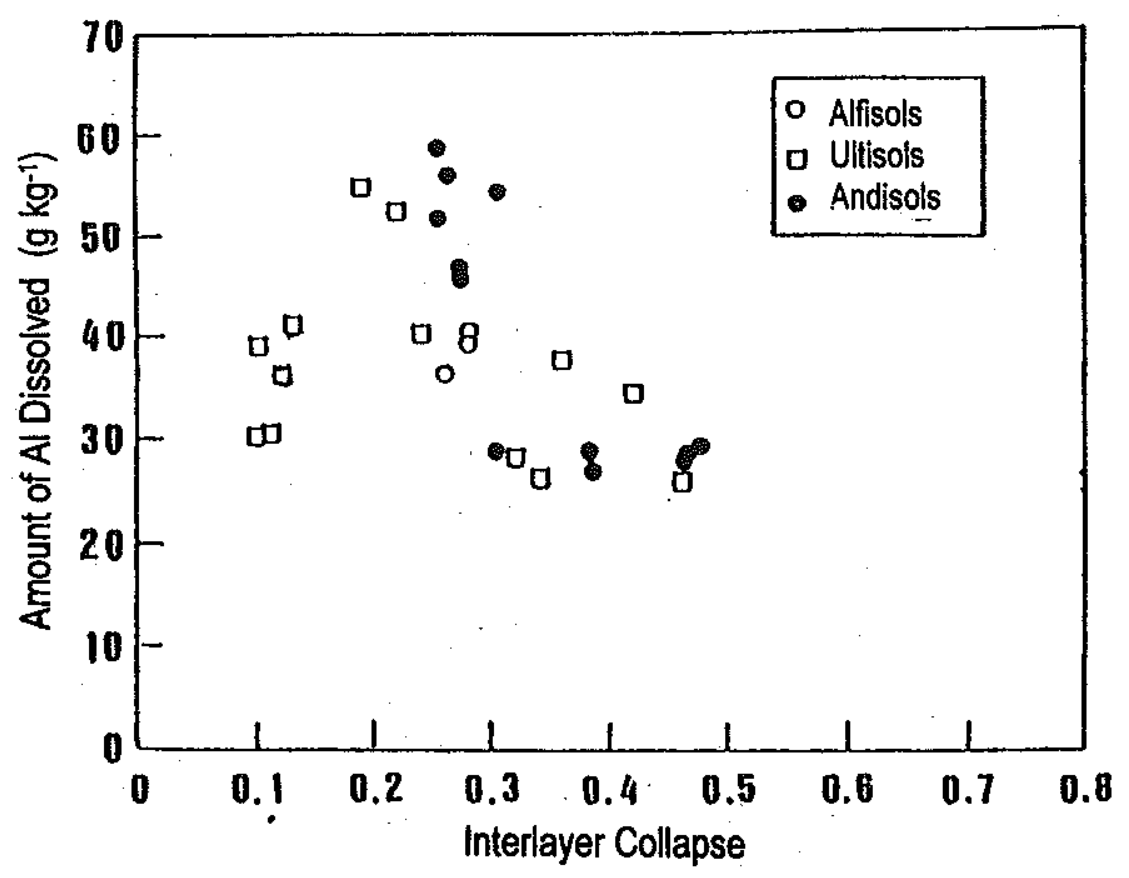

Figure 6 . Relationship between the amount of Al dissolved by $24 \mathrm{~h}$ citrate treatment after $4 \mathrm{~h}$ oxalate and interlayer collapse in Alfisols, Ulitisols and Andisols. 


\section{CONCLUSION}

This study provides evidence for the existence of hydroxyinterlayer minerals in non-allophanic Andisols and Red-Yellow Alfisols and Ultisols from Japan. The presence of hydroxy interlayer minerals was confirmed by selective dissolution treatments using $0.15 \mathrm{M}$ acid oxalate and $0.30 \mathrm{M}$ sodium citrate solutions and XRD analyses. Results of XRD analyses showed that the dominant hydroxyinterlayer minerals present in these soils consist mainly of hydroxyinterlayer vermiculite (HIV), smectite and chlorite Selective dissolution analyses indicated that the $0.3 \mathrm{M}$ sodium citrate treatment was more effective in removing the interlayer materials as compared to the $0.15 \mathrm{M}$ acid oxalate treatment.

\section{LITERATURE CITED}

BARNHISEL, R. I. and P. M. BERTSCH. 1989. Chlorites and hydroxy interlayered vermiculite and smectite. In Minerals in Soil Environments (eds. J.B. Dixon \& S.B. Weed) pp. 729-788. Soil Science Society of America, Madison.

BAUTISTA, A. T. and K. INOUE. 1993. Significance of loess addition in relation to Andic soil properties of volcanic ash soils. Soil Sci. Plant Nutr. 39:517-527.

DAVENPORT, W.H. 1949. Determination of aluminum in presence of iron - Spectrophotometric method using ferron. Anal. Chem. 21:710711.

HIGASHI, T. \& H. IKEDA. 1974. Dissolution of allophane by acid oxalate solution. Clay Science 4: 205-211. 
INOUE, K. 1990. Active aluminum and iron components in Andisols and related soils. pp. 153-158. In Trans. Int. Congr. Soil Sci. 14th, Kyoto, Japan. 12-18 Aug. 1990. Vol. 7. ISSS, Wagenitgen, The Netherlands.

INOUE, K. and T. HIGASHI. 1988. Al- and Fe-humus complexes in Andisols. pp. 81-96. In D.I. Kinloch et al. (ed.) Proc. Int. Soil Classif. Worksh. 9th, Japan. 20July - 1 Aug.1987. Soll Management Support Ser., Washington, D.C.

INOUE, K. and T. NARUSE. 1987. Physical, chemical, and mineralogical characteristics of modern eolian dust in Japan and rate of dust deposition. Soil Sci. Plant Nutr. 33:327-345.

INOUE, K. and C. SATOH. 1992. Electric charge and surface characteristics of hydroxyaluminosilicate-and hydroxyaluminumvermiculite complexes. Clays and Clay Miner. 40:311-318.

INOUE, K. and C. SATOH. 1993. Surface charge characteristics of hydroxyaluminosilicate- and hydroxyaluminum-montmorillonite complexes. Soil Sci. Soc. Am. J. 57:545-552.

INTERNATIONAL SOLL REFERENCE AND INFORMATION CENTER (ISRIC). 1987. Procedures for Soil Analysis. (L.P. van Reeuwijk, ed) Wageningen, The Netherlands.

MATSUE, N. and K. WADA. 1988. Interlayer materials of partially interlayered Vermiculites in Dystrochrepts derived from Tertiary sediments. J. Soil Sci. 39: 155-162.

MEHRA, O.P. and M.L. JACKSON. 1960. Iron oxide removal from soils and clays by a dithionite-citrate system buffered with sodium bicarbonate. Clays Clay Miner. 8:317-327. 
Tulin

SAKURAI, K. and P.M. HUANG. 1998. Intercalation of hydroxyaluminosilicate and hydroxy-aluminum in montmorillonite and resultant physicochemical properties. Soil Sci. Soc. Am. J. 62:362-368.

WADA, K. and Y. KAKUTO. 1983a. Intergradient vermiculite-kaolinite mineral in Korean Uitisol. Clays and Clay Minerals 31:183-190.

WADA, K. and Y. KAKUTO. 1983b. A new intergradient yermiculite-kaolin mineral in 2:1 to 1:1 mineral transformation. Sci. Geol. Mem. 73:123-131.

WEAVER, R.M., J.K. SYERS, and M.L. JACKSON. 1968. Determination of silica in citrate-bicarbonate extracts of soils. Soil Sci. Soc. Am. Proc. 32:497-501.

\section{ACKNOWLEDGMENT}

The author would like to thank the Ministry of Education, Science, Sport, and Culture of Japan and the Japanese Association of Student Support Services for supporting her stay in Japan and to the late Prof: Katsuhiro Inoue for mentoring and inspiring her to do researches on Soil Chemistry and Mineralogy. 


\section{ABOUT THE AUTHOR}

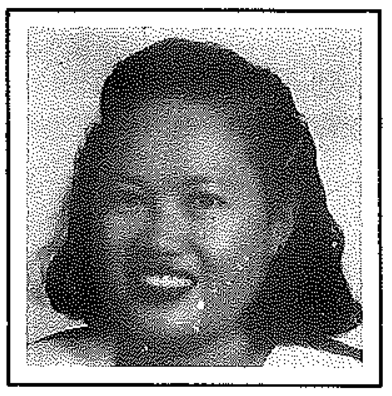

The author finished her Bachelor of Science in Agriculture degree from Leyte State University (LSU) at Baybay, Leyte. She earned her Master of Science degree major in Soil Science from the University of the Philippines at Los Baños, Laguna and her Doctor of Philosophy (Ph.D.) degree in Soil Science major in Soil Chemistry and Mineralogy at Iwate University in Japan.

Currently, she is a founding member and treasurer of Phi Delta, The Honor Society of Science at LSU, and a member of various international, national and local scientific societies and organizations. 